\title{
Sound-Producing Sand in Japan: Major Element Composition and Its Minerals Determined by X-ray Diffraction and X-ray Fluorescence
}

\author{
Chiaki IGARASH * and Naotatsu ShIKAZONo** \\ *Graduate School of Science and Technology, Keio University, 3-14-1 Hiyoshi, Kohoku-ku, \\ Yokohama 223-8522, Japan \\ **Department of Applied Chemistry, Environmental Chemistry, Keio University, 3-14-1 Hiyoshi, Kohoku-ku, \\ Yokohama 223-8522, Japan
}

\begin{abstract}
The major element composition, including two kinds of clay minerals and moisture content of sound-producing sand are reported for the first time. Sand from 33 beaches in Japan has been found to make sound. Ten sound-producing beaches were selected to compare with silent beach sand. Both sound-producing sand and silent beach sand are mostly composed of quartz and feldspar. The range of $\mathrm{SiO}_{2}$ content of sound-producing sand is not different from silent sand samples. This indicates that a high quartz content is not necessary to produce sound, although more than 60 weight percent of quartz is necessary. One silent sand recovered its sound after a 3.5 percent $\mathrm{HNO}_{3}$ treatment. Also, a small portion of clay minerals was found. A clean grain surface is a necessary factor for sand to produce sound. Illite was found in all silent sand samples.
\end{abstract}

(Received February 5, 2003; Accepted July 24, 2003)

\section{Introduction}

The sound producing-sand has been well known as musical sand, or booming sand, for thousands of years. They are distinguished in two types-booming and squeaking sand. "Booming sand" especially occurs in dune and desert regions. It produces a low-frequency sound during avalanching. "Squeaking sand" is often found on beaches, which shows a high-pitched note. The sound is produced when walking across dried beach sand. It occurs on the seacoast of every continent, ${ }^{1-3}$ island and along lakeshores. ${ }^{4}$ Japan is one of the islands surrounded by ocean, and the sound-producing sand is more common and widespread in occurrence. ${ }^{3,5-9}$ Most of the soundproducing sand beaches are found in a crescent-shape between low cliffs, and are isolated from frequency access. In a rare phenomenon, some sand forms dunes along the coast. There are many sound-producing sand beaches in Japan, but only 30 singing beaches were reported in $1997 .{ }^{10}$ The sounding mechanism and physical characteristics of the singing sand have been researched by many scientists. ${ }^{1-3,5-9,11,12}$ The mechanism of sound-producing sand has been under a veil for some time. An early hypothesis suggested that the sound is produced by a piezoelectric effect, the production of electrical currents by quartz grains under mechanical stress. ${ }^{13}$ Finally, Miwa and Hidaka ${ }^{14}$ stated that sound is produced when the grains create friction to vibrate each other. For sand to create sound, a few conditions are necessary: 1) more than $90 \%$ of quartz grains, 2) the sand must be dry, 3) clean surface and well washed, well rounded and highly spherical, 4) smooth surface, and 5) well sorted.

This paper explains the bulk chemical composition and mineralogy of sound-producing sands. The characteristics of sound producing sand and silent sand were investigated.

\section{Analytical Procedure}

All of the beach sand samples presently studied were located in Cretaceous granitic regions (Fig. 1). Samples were collected from two main regions of Japan: the Miyagi area in the Northern main land (Honshu) and the Tottori area in western Honshu. Three samples were collected from each beach surface.

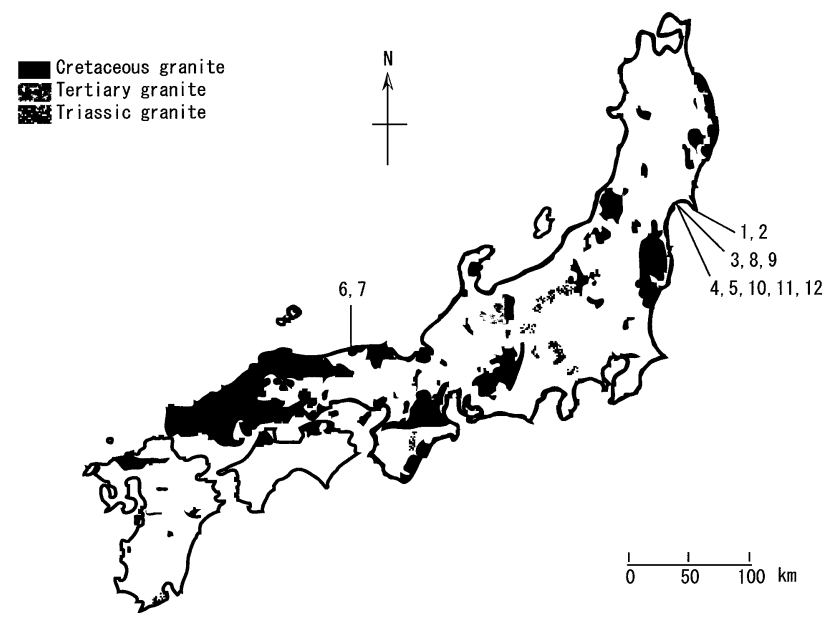

Fig. 1 Map showing the location of sound-producing sand (1 - 7) and silent sand beaches $(8-12)$ sampled in Japan. The numbers correspond to the entires listed in Table 1 . 
Table 1 Major element composition of each beach sand in weight percent

\begin{tabular}{|c|c|c|c|c|c|c|c|c|c|c|c|c|}
\hline & $\mathrm{SiO}_{2}$ & $\mathrm{TiO}_{2}$ & $\mathrm{Al}_{2} \mathrm{O}_{3}$ & $\mathrm{FeO}$ & $\mathrm{MnO}$ & $\mathrm{MgO}$ & $\mathrm{CaO}$ & $\mathrm{Na}_{2} \mathrm{O}$ & $\mathrm{K}_{2} \mathrm{O}$ & $\mathrm{P}_{2} \mathrm{O}_{5}$ & LOI & Total \\
\hline \multicolumn{13}{|l|}{ Sound producing sand } \\
\hline 1. Kugunarihama (Oshima) & 94.82 & 0.07 & 2.12 & 0.38 & 0.01 & 0.00 & 0.12 & 0.21 & 0.76 & 0.21 & 0.38 & 99.09 \\
\hline 2. Kukunakihama & 97.70 & 0.97 & 1.31 & 0.17 & 0.02 & 0.00 & 0.04 & 0.01 & 0.41 & 0.00 & 0.24 & 100.87 \\
\hline 3. Natsuhama & 99.19 & 0.09 & 4.15 & 0.42 & 0.03 & 0.00 & 0.19 & 0.76 & 1.41 & 0.00 & 0.42 & 106.64 \\
\hline 4. Takehama & 61.35 & 0.36 & 17.93 & 5.32 & 0.23 & 2.54 & 6.03 & 4.57 & 0.17 & 0.04 & 0.24 & 98.79 \\
\hline 5. Murohama & 62.62 & 0.22 & 19.82 & 2.70 & 0.09 & 1.12 & 6.38 & 5.09 & 0.23 & 0.03 & 0.19 & 98.49 \\
\hline 6. Idegahama & 68.57 & 0.21 & 16.50 & 2.24 & 0.04 & 0.94 & 4.09 & 4.04 & 2.61 & 0.06 & 0.22 & 99.51 \\
\hline 7. Aoya beach & 67.28 & 0.25 & 17.73 & 2.49 & 0.05 & 1.23 & 4.42 & 4.15 & 2.00 & 0.04 & 0.54 & 100.17 \\
\hline \multicolumn{13}{|l|}{ Silent sand } \\
\hline 8. Shirahama & 94.71 & 0.10 & 2.79 & 0.61 & 0.03 & 0.10 & 0.38 & 0.41 & 0.70 & 0.00 & 0.31 & 100.13 \\
\hline 9. Kugunarihama & 89.17 & 0.58 & 3.94 & 2.49 & 0.08 & 0.74 & 0.88 & 0.33 & 0.58 & 0.01 & 0.44 & 99.24 \\
\hline 10. Ohama & 69.44 & 0.22 & 15.29 & 3.05 & 0.10 & 1.05 & 4.49 & 3.75 & 0.56 & 0.04 & 0.57 & 98.57 \\
\hline 11. Tsukihama & 66.83 & 0.26 & 17.37 & 2.96 & 0.07 & 0.93 & 5.19 & 4.16 & 0.70 & 0.04 & 0.93 & 99.43 \\
\hline 12. Otomehama & 64.03 & 0.29 & 19.00 & 2.86 & 0.08 & 0.93 & 5.81 & 4.63 & 0.61 & 0.03 & 1.60 & 99.87 \\
\hline Albite & 64.65 & 0.00 & 19.43 & 0.04 & 0.00 & 0.03 & 0.38 & 3.71 & 10.97 & 0.00 & & \\
\hline Anorthite & 43.79 & 0.00 & 35.79 & 0.43 & 0.00 & 0.33 & 18.69 & 0.42 & 0.03 & 0.00 & & \\
\hline Quartz & 99.53 & 0.00 & 0.02 & 0.10 & 0.00 & 0.00 & 0.00 & 0.00 & 0.00 & 0.00 & & \\
\hline Illite & 49.84 & 0.03 & 30.98 & 7.79 & 0.00 & 0.00 & 1.17 & 10.02 & 0.00 & & & \\
\hline Montmorillonite & 69.39 & 0.10 & 20.53 & 1.47 & 0.08 & 0.00 & 5.75 & 2.96 & 0.17 & 0.00 & & \\
\hline fresh granite/Kitakami & 64.92 & 0.56 & 15.18 & 5.39 & 0.11 & 1.99 & 4.24 & 3.20 & 2.61 & 0.11 & & \\
\hline fresh granite/Sanin & 72.39 & 0.24 & 14.01 & 2.49 & 0.05 & 0.44 & 2.40 & 3.86 & 3.00 & 0.05 & & \\
\hline
\end{tabular}

\section{$X$-ray fluorescence $(X R F)$}

Each sample was washed with $3.5 \% \mathrm{HNO}_{3}$ to rid of its carbonates, dried at room temperature for about $24 \mathrm{~h}$, then milled and powdered with an automatic pot mill for about 15 min to determine any loss of ignition (LOI). The powdered samples were completely dried for $24 \mathrm{~h}$ at $900^{\circ} \mathrm{C}$ in a muffle oven. Samples were prepared for major-element analysis using fused lithium tetraborate glass disks. Pt-Au crucibles were used for the fusion, then melted in air at $1100^{\circ} \mathrm{C}$ for $\sim 10$ min with constant agitation to ensure through mixing, and then cooled. A wavelength-dispersive X-ray spectrometer (Rigaku), equipped with $\mathrm{Rh}$-anode $\mathrm{X}$-ray tubes, was used to determine the major element abundances in the samples. The spectrometer was calibrated using well-analyzed standard JG-2 and JB-1b of the Geological survey of Japan.

\section{$X$-ray powder diffraction}

The samples were air dried and milled for X-ray powder diffraction method. The mineral compositions of sands were determined by an X-ray powder diffraction (Rigaku) method in the range $4-60^{\circ} \mathrm{C}$ with $\mathrm{Cu} \mathrm{K}_{\alpha}$ under $50 \mathrm{kV}$ and $60 \mathrm{~mA}$.

The sticking complements on grains were also measured by powder X-ray diffraction. To see the properties of beach sand, some experiments were reinforced. Five mixtures, bentnite (Junsei Chemical Co., Ltd.), which is mostly composed of very fine-grained montmorillonite and Illite, Iron(III) hydroxide (Junsei Chemical Co., Ltd.), loam (red soil), silent sand and calcite were added to sound-producing sand up to several percent by weight.

\section{Results}

The yielded weight percentages of each averaged major component for the different beach samples are given in Table 1 . All sound-producing sand contained more than $50 \%$ of $\mathrm{SiO}_{2}$. Only one silent sand, Shirahama in Miyagi, produced sound after washing with $\mathrm{HNO}_{3}$ acid.

Because the beach sand is a product of the breakdown of coarse-grained source rocks, granite and granitic sandstone supplied mostly quartz and feldspar (Table 1). The sticking materials are given in Table 2. Each type of beach sand contains mostly quartz and clay minerals on its surface.

The addition of more than $0.1 \%$ of the sample weight of the first three mixtures destroyed the sound. More than $0.4 \%$ of silent sand and calcite made a feeble sound (Table 3). Next, 1 weight $\%$ of the moisture of distilled water was added to the each sound-producing sand. It made a feeble sound. Less than $1 \%$ of moisture made the sound clearly.

\section{Discussion}

The major element composition of sound-producing sand determined in this study are compared to the composition of selected silent sand in Table 2 and three graphs in Fig. 2. In general, the composition of sound-producing sand shows a high concentration of $\mathrm{SiO}_{2}$, more than 90 weight $\%$. Our samples showed more than 61 weight $\%$ of $\mathrm{SiO}_{2}$ concentration in soundproducing sand, as did the silent sand. The concentration of $\mathrm{SiO}_{2}$ in silent sand ranged from 66.8 to 94.7 weight\%. The relatively high $\mathrm{SiO}_{2}, \mathrm{Al}_{2} \mathrm{O}_{3}$ and $\mathrm{Na}_{2} \mathrm{O}$ composites were quartz and feldspar.

A plot of $\mathrm{Al}_{2} \mathrm{O}_{3}$ vs. $\mathrm{SiO}_{2}, \mathrm{Al}_{2} \mathrm{O}_{3}$ vs. $\mathrm{CaO}$ and $\mathrm{Al}_{2} \mathrm{O}_{3}$ vs. $\mathrm{Na}_{2} \mathrm{O}$ (Fig. 2) reveals important characteristics of beach sands. The sands in this figure are divided into two classes with respect to their $\mathrm{SiO}_{2}$ and $\mathrm{Al}_{2} \mathrm{O}_{3}$ composition. A negative correlation of $\mathrm{Al}_{2} \mathrm{O}_{3}$ vs. $\mathrm{SiO}_{2}$ indicates that the beach sand is composed of mainly quartz and feldspar, and a positive correlation between $\mathrm{Na}_{2} \mathrm{O}$ and $\mathrm{Al}_{2} \mathrm{O}_{3}$ is due to the Na-feldspar content.

A high quartz/feldspar ratio automatically suggests that almost all of the unstable minerals had been removed by chemical weathering, erosion or transportation by river water. The ratio cannot tell much about the original source rock composition if the sand derived from it is all quartz, because there is a limit as to how closely quartz varieties correspond to rock compositions. It is difficult to distinguish that these quartz grains were not derived by erosion of an older granite exposed at the surface. 
Table 2 Major minerals and wrapping clay minerals of the sound-producing sand and the silent sand

\begin{tabular}{|c|c|c|c|c|c|c|c|}
\hline \multirow[b]{2}{*}{ Location } & \multicolumn{2}{|c|}{ Major minerals } & \multicolumn{5}{|c|}{ Wrapping clay minerals } \\
\hline & Quartz & Feldspar & Illite & Hornblen & Chamosite & Biotite & Muscovite \\
\hline \multicolumn{8}{|l|}{ Sound producing sand beach } \\
\hline 1. Kugunarihama (Oshima) & rich & poor & 0 & & $\triangle$ & $\triangle$ & \\
\hline 2. Kukunakihama & rich & poor & 0 & & $\triangle$ & $\triangle$ & \\
\hline 3. Natsuhama & rich & poor & & & & $\triangle$ & $\triangle$ \\
\hline 4. Takehama & poor & & & & & $\triangle$ & \\
\hline 5. Murohama & poor & & & $\triangle$ & & & \\
\hline \multicolumn{8}{|l|}{ Sound reproducing sand } \\
\hline 8. Shirahama & rich & poor & $\bigcirc$ & $\triangle$ & $\triangle$ & $\triangle$ & \\
\hline \multicolumn{8}{|l|}{ Silent sand beach } \\
\hline 9. Kugunarihama(Oshika peninsula) & rich & poor & 0 & $\triangle$ & $\triangle$ & & \\
\hline 10. Tsukihama & poor & rich & $\bigcirc$ & & & & \\
\hline 11. Ohama & poor & rich & 0 & & & & \\
\hline 12. Otomehama & rich & rich & $\bigcirc$ & & & & \\
\hline
\end{tabular}

The open circle indicates a remarkabke mineral and the triangle is a second remarkable mineral.

Table 3 Five different samples are added to sound-producing sand

\begin{tabular}{lcccccc}
\hline \multirow{2}{*}{ Sample } & \multicolumn{7}{c}{ Amount added/gram } \\
\cline { 2 - 7 } & 0.01 & 0.02 & 0.03 & 0.04 & 0.05 & 0.06 \\
\hline Bentnite & $\bigcirc$ & $\times$ & $\times$ & $\times$ & $\times$ & $\times$ \\
FeO(OH) & $\times$ & $\times$ & $\times$ & $\times$ & $\times$ & $\times$ \\
Silent sand & $\bigcirc$ & $\bigcirc$ & $\bigcirc$ & $\triangle$ & $\times$ & $\times$ \\
Calcite & $\bigcirc$ & $\bigcirc$ & $\bigcirc$ & $\triangle$ & $\times$ & $\times$ \\
Loam & $\triangle$ & $\times$ & $\times$ & $\times$ & $\times$ & $\times$ \\
\hline
\end{tabular}

A small grain, such as bentnite, $\mathrm{FeO}(\mathrm{OH})$ or soil destroyed the sound; even $0.1 \%$ was added by weight (indicated with $\times$ ).

The open circle indicates the sound and the triangle indicates a feeble sound.

The importance of cleanness of the grain surface has been noticed by many researchers. ${ }^{2,4,12}$ There are some sticking minerals, including clay minerals, found in each of the beach sands (Table 2). The cleanness of the grain surface is an important factor for sand to make sound; however, it seems that a small portion of any contamination on the surface does not affect the sound process. The results of solid experiments (Table 3) also provide that a few, less than $0.1 \%$ by weight, surface contaminations do not influence the sand to produce sound.

A very dry condition is required for the sounding process. Our experiments found that as a unique consequence, a drop of moisture, less than 0.1 weight $\%$, creates the friction between grains to vibrate each other, thus creating sound (Table 4). The sound-producing mechanism of beach sand is effective under $0.1 \%$ wet by weight or dry conditions, but much more effective when the sand is dry.

\section{Conclusions}

Our study on sound-producing sand in Japan indicates that at least 60 weight $\%$ of quartz grains are necessary for sand to produce sounds. XRD and XRF analyses indicate that major minerals are quartz and feldspar for both sound-producing sand and silent sand. Small amounts of clay minerals are present in both sound-producing sand and silent sand. Illite is found in the
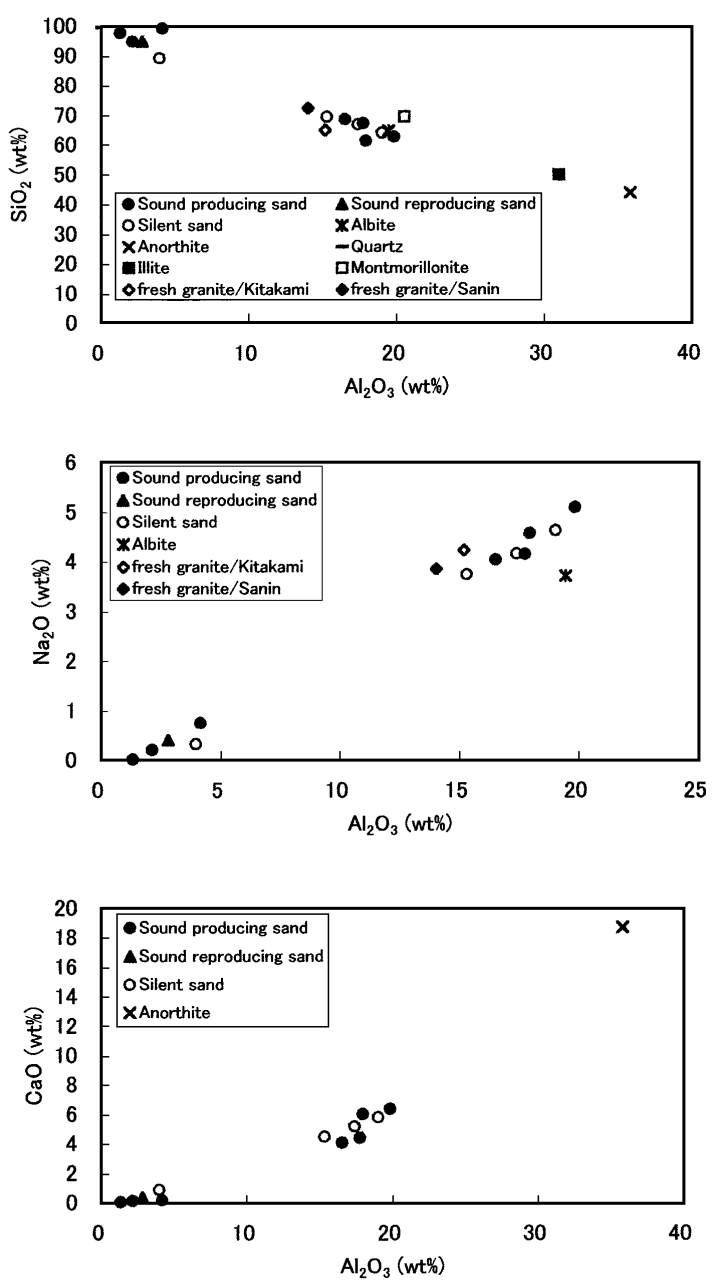

Fig. 2 Three diffemet chemical compositions normalized to the $\mathrm{Al}_{2} \mathrm{O}_{3}$ values of each sample. A) $\mathrm{SiO}_{2}$ vs. $\mathrm{Al}_{2} \mathrm{O}_{3}$ for the soundproducing sand and silent sand. B) $\mathrm{Na}_{2} \mathrm{O}$ vs. $\mathrm{SiO}_{2}$. C) $\mathrm{CaO}$ vs. $\mathrm{Al}_{2} \mathrm{O}_{3}$ Each symbols correspond to the entires listing in Table 1.

surface of all silent sand samples. 0.1 weight\% of contamination, such as clay minerals, iron hydroxide and soil, destroyed the sound. 0.4 weight $\%$ of silent sand and calcite 
Table 4 Ten different values of water are added to each $10 \mathrm{~g}$ of 7 sound producing sand samples

\begin{tabular}{lllllllllll}
\hline \multicolumn{1}{c}{ Amount added/ml } & 0.01 & 0.02 & 0.03 & 0.04 & 0.05 & 0.06 & 0.07 & 0.08 & 0.09 & 1.00 \\
\hline Sound producing sand & & & & & & & & & & \\
1. Kugunarihama(Oshima) & $\bigcirc$ & $\bigcirc$ & $\bigcirc$ & $\bigcirc$ & $\bigcirc$ & $\bigcirc$ & $\bigcirc$ & $\triangle$ & $\triangle$ & $\times$ \\
2. Kukunakihama & $\bigcirc$ & $\bigcirc$ & $\bigcirc$ & $\bigcirc$ & $\bigcirc$ & $\bigcirc$ & $\bigcirc$ & $\triangle$ & $\triangle$ & $\times$ \\
3. Natsuhama & $\bigcirc$ & $\bigcirc$ & $\bigcirc$ & $\bigcirc$ & $\bigcirc$ & $\bigcirc$ & $\triangle$ & $\triangle$ & $\times$ & $\times$ \\
4. Takehama & $\bigcirc$ & $\bigcirc$ & $\bigcirc$ & $\bigcirc$ & $\bigcirc$ & $\bigcirc$ & $\bigcirc$ & $\triangle$ & $\triangle$ & $\times$ \\
5. Murohama & $\bigcirc$ & $\bigcirc$ & $\bigcirc$ & $\bigcirc$ & $\bigcirc$ & $\bigcirc$ & $\triangle$ & $\triangle$ & $\times$ & $\times$ \\
6. Idegahama & $\bigcirc$ & $\bigcirc$ & $\bigcirc$ & $\bigcirc$ & $\bigcirc$ & $\bigcirc$ & $\triangle$ & $\triangle$ & $\times$ & $\times$ \\
7. Aoya beach & $\bigcirc$ & $\bigcirc$ & $\bigcirc$ & $\bigcirc$ & $\bigcirc$ & $\bigcirc$ & $\triangle$ & $\triangle$ & $\times$ & $\times$ \\
\hline
\end{tabular}

1 weight $\%$ of water/moisture made a feeble sound $(x)$. Clear sound is indicated by an open circle, and a feeble sound by a triangle.

made a feeble sound. The sound-producing beach sand produces sound under $0.1 \%$ wet or dry conditions, although it is much more effective when the sand is dry.

\section{Acknowledgements}

We thank Mr. Koei Igarashi and Mrs. M. Igarashi for collecting some of the sand samples. We also wish to thank Andy Young for his comments on research papers.

\section{References}

1. H. C. Bolton and A. A. Julian, Science, 1883, 2(43), 713.

2. J. F. Lindsay, D. R. Criswell, and B. S. Criswell, Geo. Soc. Am. Bull., 1976, 87, 463.

3. S. Miwa and T. Ozaki, Sound Dune Research 42 (in
Japanese), 1995, 20

4. W. D. Richardson, Science, 1919, Nov. 28

5. K. Niiobi, Tohoku Kenkyu (in Japanese), 1960, 10(6), 9.

6. K. Niiobi, Chigaku Kenkyu (in Japanese), 1963, 14(5), 142. (in Japanese)

7. Y. Onuki, O. Shibuya, and K. Watanabe, Tohoku Kenkyu (in Japanese), 1963, 14(7), 64.

8. Y. Onuki, O. Shibuya, and S. Suzuki, Chigaku Kenkyu (in Japanese), 1966, 17(3), 77.

9. Y. Onuki and O. Shibuya, Chigaku Kenkyu (in Japanese), 1971, 22(11,12), 338

10. National Trust of Japan, "Report on Sound producing sand beach in Japan (in Japanese)", 1997.

11. R. S. Tarr, Science, 1883, 2(45), 764.

12. F. Nori, M. Bretz, and P. Sholtz, Sci. Amer., 1997, 3, 84.

13. R. A. Bagnold, Proc. Roy. Soc. A, 1966, 295, 219.

14. S. Miwa and S. Hidaka, Kagakukougaku Ronbunshu (in Japanese), 1981, 7(2), 184. 